\author{
Professor Constantin ANGHELACHE, PhD \\ E-mail: actincon@yahoo.com \\ The Bucharest University of Economic Studies \\ Associate Professor Mădălina-Gabriela ANGHEL, PhD \\ E-mail: madalinagabriela_anghel@yahoo.com \\ "ARTIFEX" University of Bucharest \\ Lecturer Ștefan Virgil IACOB, PhD \\ E-mail: stefaniacob79@yahoo.com \\ "ARTIFEX" University of Bucharest
}

\title{
MODEL FOR ANALYSIS AND CONSTRUCTION OF THE EFFICIENT PORTFOLIOS
}

\begin{abstract}
Portfolios can always be invested and must be invested by the entities concerned, in order to be as efficient as possible. The efficiency of a portfolio is measured by the profitability with which it is completed. Therefore, a portfolio involves at least two securities, which do not provide a definite return for materialization, but each time the question arises to determine in advance what will be the level of return of this portfolio.

The portfolio can be composed entirely of a single security, without any problem regarding the existence of any correlation or any situation of covariance. It is very rare for a securities portfolio to be based on a single security and in most cases they are considered securities synthesized in a portfolio. The measurement of the efficient portfolio is done through econometric models taking into account the securities that are correlated and that give the possibility of a combination based on which to ensure the lowest possible return. The standard portfolio analysis situations are quite difficult to interpret and therefore the answers are limited to each portfolio, from which we can deduce on the basis of econometric studies the expected return or expected profitability.

In conclusion, we can appreciate that the analysis model and the construction of the portfolio must be one built and used according to the perceptions that such a study implies.
\end{abstract}

Keywords: investments, portfolios, assets, securities, profitability, investors, capital market, deviations, models and econometric methods.

JEL Classification: C13, G11, G17

1. Introduction

In the article Model of analysis and construction of efficient portfolios, the authors presented in detail some international concepts based on which a study can

DOI: 10.24818/18423264/55.2.21.19 
be made using well-founded econometric models. We say well-founded at least from a theoretical point of view, because a number of great economists such as Markowitz, Akaike and others have established with great precision the context in which efficient portfolios can be built, which meet the requirements of investors in terms of expected returns.

The econometric models built and exemplified in this study on which this article is based, discuss a series of variants that are analyzed, dissected and based on which a series of conclusions are expressed that can lead to stability and precise thinking.

Decisions regarding the investment placement of securities portfolios must be based primarily on eliminating uncertainty, which can affect the final return. In this sense, we can say that there is a standard deviation of the variation of the final yield, a situation that can be solved by using concepts, which should be the basis of the econometric model used.

The article used a series of models, graphical representations, with the necessary explanations to emphasize the practical way of making these portfolios that we talked about.

\section{Literature review}

This article is based on an extensive literature that addresses this topic. The issue is very important, especially in the current conditions when the world economy is undergoing a process of contraction as a result of the pandemic crisis combined with the economic-financial one, which is in a wide expansion process, not only in Romania but also in all the states of the world. A series of analyzes were performed on this topic, studies were performed and a lot of hypotheses were issued. A number of substantial works have been published domestically and internationally. Thus, Altăr M. (2002) approached in detail the theory of portfolios in which he clarifies the most significant elements on this topic. Amenc N. and Le Sourd V. (2003) extensively approached portfolio theory and analyzed their performance, and Amuer H.B. and Prigent J.L. (2010) have dedicated an extensive study on the structural management of portfolios. Armeanu D. (2008) published an article on the profitability and risk of the portfolio consisting of two titles. Baule R. (2010) conducts a study on the selection of the optimal portfolio for a small investor, considering the risk and cost of the transaction. Buraschi A., Porchia P. and Trojani F. (2006) address the correlation of risk with the optimal chosen portfolio and Campbell J.V. together with Viceira L.M. (2002) analyzes the strategy of allocating shares in case of choosing the portfolio for long-term investments. In 2009 Clemencon S., Skanderbeg S. conducted and published a study on the selection of a portfolio at extreme risk of measurement. In turn, Cox J. and Huang C.F. (1989) analyses the optimal consumption and policies of placing portfolios according to stock prices. Dragota V., Dragota M., Damian OA, Stoian A., Mitrica E., Lacatus CM, Mante D., Tâșu L. and Hândoreanu CA (2009)

DOI: $10.24818 / 18423264 / 55.2 .21 .19$ 
published the paper management of the securities portfolio, in which they make an extensive presentation of how to manage securities portfolios. Geromichalos A., Simonovska I. (2011) analyze a number of aspects regarding the liquidity of assets in the formation of international portfolios, Harvey, CR and others focus on the analysis of portfolio selection with high moments, and Iacob SV, Dumitru D., Popovici M (2020) pay attention in their study to issues related to the choice of portfolios and testing in a model the price of capital assets. Li J. and Smetters K. (2011), study a number of issues regarding the choice of the optimal portfolio in the context of ensuring Social Security indexation. Markowitz H. (1959) studies and publishes extensive material on portfolio selection in the context of investment diversification. Merton R.C. (1971) published a study on optimal consumption and portfolio rules when using a continuous time model and Stancu I. (2007) published a paper presenting a study on the financial market and portfolio management. West K.D. (2012) makes a presentation on the econometric analysis of the use of a model when the reduction factor is close to one.

\section{Data, results and discussions}

Portfolios are composed of securities. In order to understand portfolios, one must know the effects of combining securities. If we consider a portfolio involving two securities, which does not provide a definite return for materialization, we assume that the securities of financial instruments 1 have a lower expected return and a standard deviation of the return from the securities 2, so that:

$N=2 ; E_{1}<E_{2}$ and $0<\sigma_{1}<\sigma_{2}$

A portfolio is characterized by the proportions invested in the two securities, which must together add up to 1 or $100 \%$, as expressed in the form of a coefficient or percentage. Thus, we have the relation:

$X_{1}+X_{2}=1$

These data are represented in figure number 1 :

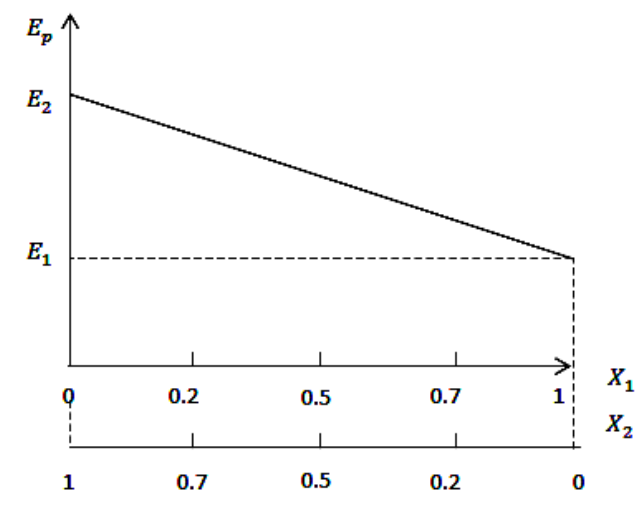

Figure 1. Proportions invested in two securities

\section{DOI: $10.24818 / 18423264 / 55.2 .21 .19$}


The expected return depends on the proportions invested in the securities, respectively:

$$
E_{p}=X_{1} E_{1}+X_{2} E_{2}
$$

Where: $E_{p}=$ profitability (yield);

$E_{1}, E_{2}=$ profitability (yield) related to each security;

$X_{1}, X_{2}=$ securities considered.

Figure number 1 shows the relationship between $E_{p}$ (represented on the vertical axis) and $X_{1}$ or $X_{2}$ (represented on the horizontal axis). The choice of a portfolio can be considered the selection of a value for $X_{1}$, because $X_{2}=1-X_{1}$. Alternatively, the selection of a value for $X_{2}$ can be considered, because $X_{1}=1$ $X_{2}$. In this case only positive or zero values are considered.

The expected profitability is linearly related to $X_{1}\left(\operatorname{or} X_{2}\right)$. This must be the case, whatever the forecasts for the expected return on the securities. The standard deviation of profitability is related to the composition of the portfolio, a situation in which we can consider the relationship:

$$
\sigma_{p}^{2}=X_{1}^{2} \sigma_{1}^{2}+X_{2}^{2} \sigma_{2}^{2}+2 X_{1} X_{2} \rho_{1,2} \sigma_{1} \sigma_{2},
$$

Where: $\sigma_{p}^{2}, \sigma_{1}^{2}, \sigma_{2}^{2}=$ standard deviation of profitability

Abstracting we will conclude that:

$$
\sigma_{p}=\sigma_{1} \text { if } X_{1}=1 \text { and } X_{2}=0 ; \sigma_{p}=\sigma_{2} \text { if } X_{1}=0 \text { and } X_{2}=1
$$

In these special cases, in which the portfolio is composed entirely of a single security, the correlation is irrelevant. However, in general, $\sigma_{p}$ will depend on the extent to which the rates of return of the two securities are correlated.

If we consider the situation in which the profitability rates are perfectly correlated respectively $\rho_{1,2}$ is equal to 1 , then we can formalize it by the relation:

$$
\sigma_{p}^{2}=X_{1}^{2} \sigma_{1}^{2}+X_{2}^{2} \sigma_{2}^{2}+2 X_{1} X_{2} \sigma_{1} \sigma_{2}
$$

Rewriting the above relationship results mathematically $\sigma_{p}^{2}=\left(X_{1} \sigma_{1}+\right.$ $\left.X_{2} \sigma_{2}\right)^{2}$ and therefore extracting the radical leads to the formula:

$\sigma_{p}=X_{1} \sigma_{1}+X_{2} \sigma_{2}$

Line $\mathrm{AB}$ in figure number $2 a$ shows the relationship between $\sigma_{p}$ (represented on the vertical axis) and $X_{1}$ or $X_{2}$ (represented on the horizontal axis) when $\rho_{1,2}=1$. Only in this case, $\sigma_{p}$ is considered linear up to $X_{1}\left(\right.$ or $\left.X_{2}\right)$.

How should we analyze this relationship, if the yields are not perfectly correlated? Starting from the general formula,

$\sigma_{p}^{2}=X_{1}^{2} \sigma_{1}^{2}+X_{2}^{2} \sigma_{2}^{2}+\left(2 X_{1} X_{2} \sigma_{1} \sigma_{2}\right) \rho_{1,2}$

And whereas the expression in brackets will be positive if part of each security is retained $\left(X_{1}>0\right.$ and $\left.X_{2}>0\right)$ and none of the securities suggest a certain return $\left(\sigma_{1}>0\right.$ and $\left.\sigma_{2}>0\right)$. 

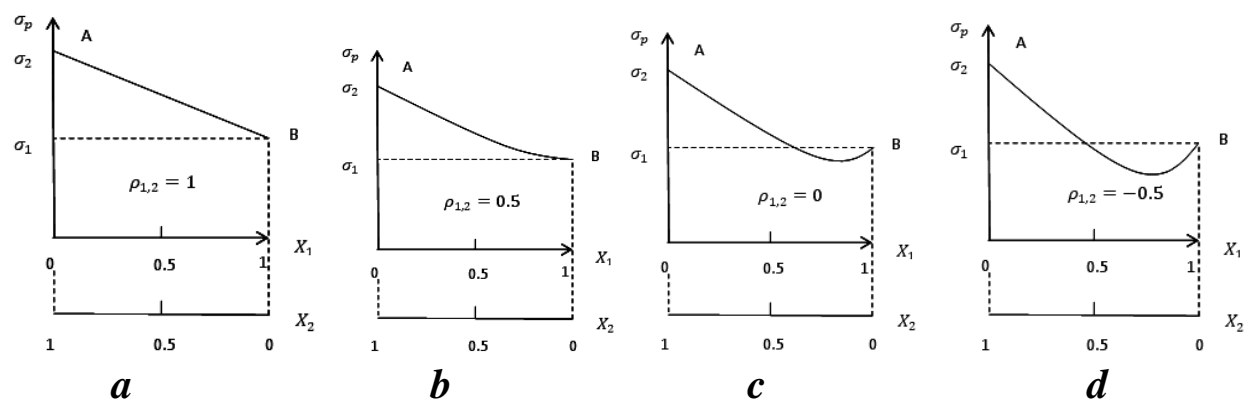

Figure 2. Relationship between $\sigma_{p}$ and $X_{1}, X_{2}$ for its various values $\rho_{1,2}$

In such conditions, a portfolio considered, how $\rho_{1,2}$ is smaller, the smaller will be $\sigma_{p}^{2}$ and thus the smaller the $\rho_{1,2}$ the smaller will be $\sigma_{p}$.

Figure $2 b$ to $d$ shows the relationship between $\sigma_{p}$ and $X_{1}$ or $X_{2}$ for cases where $\rho_{1,2}=+0.5 ; 0$ and -0.5 . As shown in Figure $2 c$, if the rates of return on securities are not correlated, some portfolio combinations will provide a standard deviation in yield, lower than any of the securities taken individually. In such situations, diversification is particularly useful. benefit.

We can appreciate that the weaker the correlation, the greater the potential

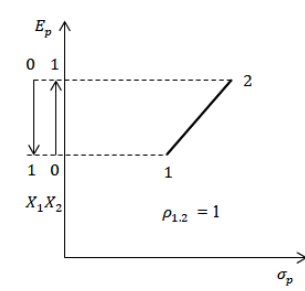

a

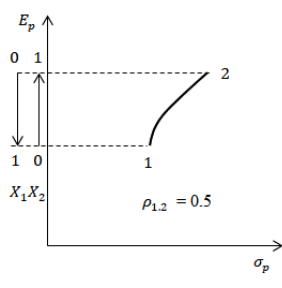

$b$

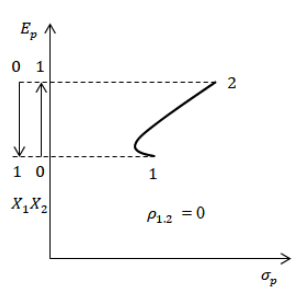

c

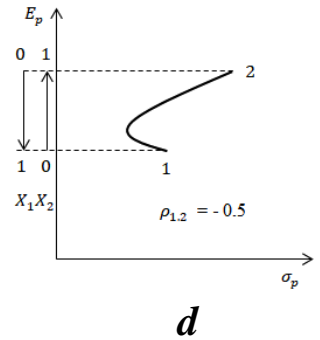

Figure 3. The values of $E_{p}, \sigma_{p}$ associated with possible combinations of the two securities

Figure $3 a$ to $d$ summarizes the relationships shown in Figures 1 and 2 for the four cases where $\rho_{1,2}=1 ; 0.5 ; 0$ and -0.5 . The curve in each graph shows the values $E_{p}, \sigma_{p}$ associated with possible combinations of the two securities. In figure number $3 c$ and $b$, all combinations are effective.

The correlation coefficient must be less than the ratio between the lowest and highest standard deviation of the values. In this case we can formalize through the relation:

$$
\rho_{1,2}<\frac{\sigma_{1}}{\sigma_{2}}=0.5
$$

The values $E_{p}, \sigma_{p}$ in graphs 2 and 3 represented on the resulting curve are efficient. The composition of the portfolio corresponding to each item can be

DOI: 10.24818/18423264/55.2.21.19 
determined from its anticipated return. Axes indicating the values of $X_{1}$ and $X_{2}$ associated with each value of $E_{p}$ are included in the diagrams to illustrate the relationship to be established.

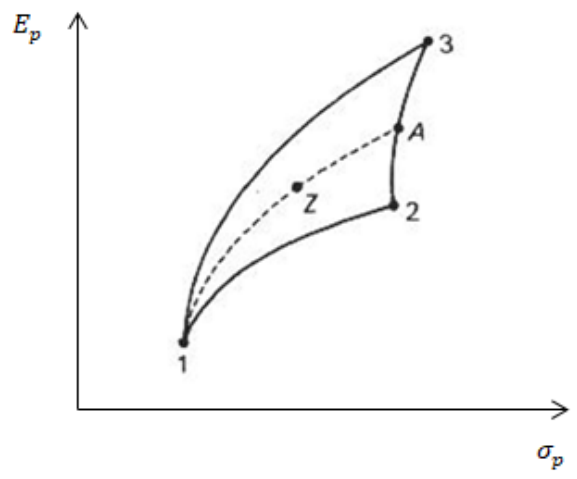

Figure 4. Diagram of the case with three securities

Figure 4 shows the analysis of a case comprising three securities. Portfolios composed entirely of securities 1 and 2 offer $E_{p}, \sigma_{p}$ combinations located on curve 1-2. Portfolios composed entirely of securities 2 and 3 offer combinations located on curve 2-3. Those composed entirely of titles 1 and 3 offer combinations located on curve 1-3.

We will consider the portfolio of equal shares of securities 2 and 3 , represented by point $\mathrm{A}$ in figure number 4 . We assume that an investor sets up a mutual fund, investing the money equally in securities 2 and 3. Future returns will be distributed to shareholders the fund, without any deduction for management fees. It is clear that a share in the fund is equivalent to holding equal amounts of securities 2 and 3. Similarly, the investor can act as his own mutual fund 1. It is possible to combine securities A with any other. For example, consider a portfolio composed of equal parts of A and security 1 :

$X_{A}=0.5$ and $X_{1}=0.5$

Although in the study the transaction costs may not be recommended, at this stage, simplifying, such costs are not included in the analysis.

We will consider the original securities to be the following:

$X_{1}=0.5 ; X_{2}=0.25$ and $X_{3}=0.25$

The question is what combination $E_{p}, \sigma_{p}$ will provide such a portfolio. The answer depends on the correlation between the profitability of $\mathrm{A}$ and that of the security 1 . If the yields are correlated, the combination will be along a line connecting points $\mathrm{A}$ and 1 . If they are not correlated it will be above and to the left of the line.

Suppose that points $\mathrm{A}$ and $\mathrm{B}$ in figure number 5 represent the values $E_{p}, \sigma_{p}$ associated with two portfolios. The values $E_{p}, \sigma_{p}$ for the combinations of A and B will stand along a curve that connects the two points. If the yields of the two 
portfolios are perfectly correlated, the curve will be a straight line. Otherwise, it will be above and to the left of the line connecting the dots.

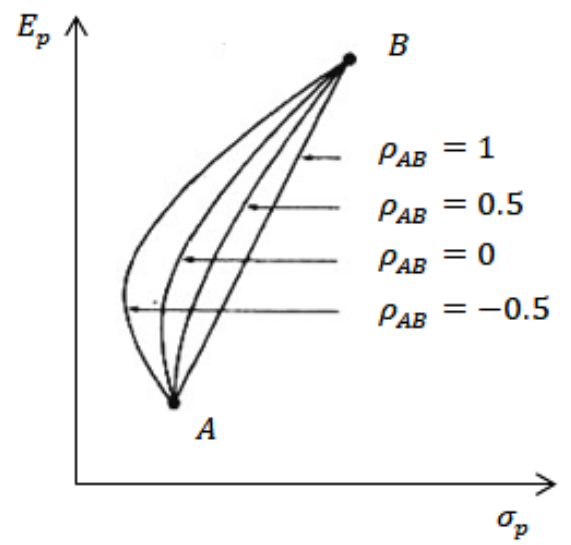

Figure 5. Correlation of portfolio returns A and B

We will further analyze a portfolio consisting of other portfolios. Suppose that $\mathrm{C}$ is such a portfolio, described by: $X_{A}$ - the proportion invested in portfolio $A$ and $X_{B}$ - the proportion invested in portfolio $B$, provided that:

$X_{A}+X_{B}=1$

Suppose $X_{i}^{A}$ the proportion of portfolio $A$ invested in the security $i, X_{i}^{B}$ the proportion of portfolio $B$ invested in securities $i$, and $X_{i}^{C}$ the proportion of portfolio $C$ invested in securities $i$, under the conditions:

$$
\sum_{i=1}^{N} X_{i}^{A}=1 ; \sum_{i=1}^{N} X_{i}^{B}=1 \text { and } \sum_{i=1}^{N} X_{i}^{C}=1
$$

The proportion of portfolio $C$ invested in any security will be a weighted average of the proportions of portfolios $A$ and $B$ invested in the security, respectively:

$$
X_{i}^{C}=X_{A} X_{i}^{A}+X_{B} X_{i}^{B}
$$

Table number 1 provides an example in which $N=4, X_{A}=0.2$ and $X_{B}=0.8$.

Table 1. Proportion of invested portfolios

\begin{tabular}{|c|c|c|c|}
\hline $\begin{array}{c}\text { Security } \\
(i)\end{array}$ & $\begin{array}{c}\text { Proportion of } \\
\text { portofolio A }\left(X_{i}^{A}\right)\end{array}$ & $\begin{array}{c}\text { Proportion of } \\
\text { portofolio B }\left(X_{i}^{B}\right)\end{array}$ & $\begin{array}{c}\text { Proportion of } \\
\text { portofolio C }\left(X_{i}^{C}\right)\end{array}$ \\
\hline 1 & 0 & 0.3 & 0.24 \\
\hline 2 & 0.5 & 0.2 & 0.26 \\
\hline 3 & 0.2 & 0.4 & 0.36 \\
\hline 4 & 0.3 & 0.1 & 0.14 \\
\hline Total & 1 & 1 & 1 \\
\hline
\end{tabular}

Figure number 6 shows the composition of each combination of the two portfolios. The figure reflects that the portfolio obtained in this way is a linear combination of the two portfolios.

DOI: 10.24818/18423264/55.2.21.19 


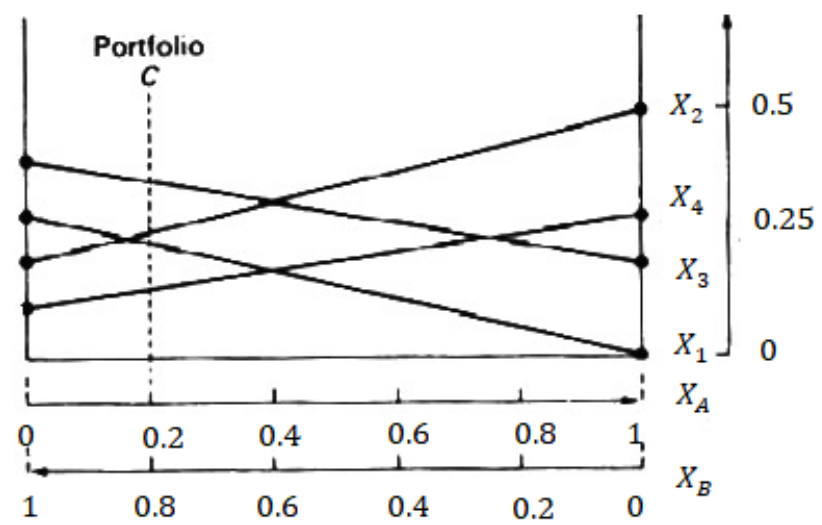

Figure 6. Combinations of the two portfolios

Any security can be specified by a point in a diagram $E_{p}, \sigma_{p}$. The same goes for the portfolio. Depending on the constraints placed on the investor, only some portfolios will be feasible (legal and achievable). In general, any combination of two feasible portfolios will also be feasible. In this case the points that represent the feasible portfolios will represent a certain area of the diagram $E_{p}, \sigma_{p}$. The area will be convex at the top (effective).

Returning to figure number 4 we can specify why there will be a dense cloud of points in the area. Suppose that points 1,2 and 3 represent three feasible portfolios. Curves 1-2, 2-3 and 1-3 indicate the combinations $E_{p}, \sigma_{p}$ resulting from the combination of portfolios 1 and 2, 2 and 3 and 1 and 3. If we consider an arbitrary point, such as $\mathrm{Z}$, inside the area, it results that a combination of the three portfolios will have the desired values of $E_{p}$ and $\sigma_{p}$. In this case, it can be seen as a combination of portfolios 1 and $\mathrm{A}$, the latter being in itself a combination of portfolios 2 and 3 .

The area $E_{p}, \sigma_{p}$ will be convex along its efficient line. This means that the area could expand, but it will never collapse along this line.

In this sense let us consider $\mathrm{V}$ and $\mathrm{W}$ two points of $E_{p}, \sigma_{p}$ efficient. All points between $\mathrm{V}$ and $\mathrm{W}$ will be located on or above a line connecting the two points.

Figure $7 a$ and $b$ show the possible cases. Figure number $7 c$ shows an impossible case. The situation shown in Figure $7 c$ is impossible, because a portfolio made by combining portfolios $V$ and $W$ will have values $E_{p}$ and $\sigma_{p}$ located along the line $V W$ (in case of perfect correlation) or above it. Such a point will dominate one or more points along the supposedly effective border. 


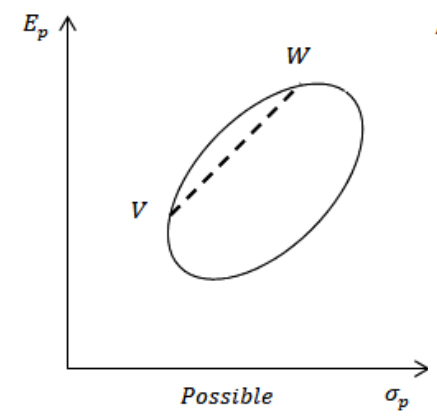

a

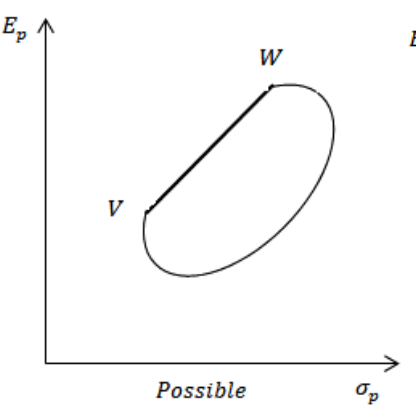

b

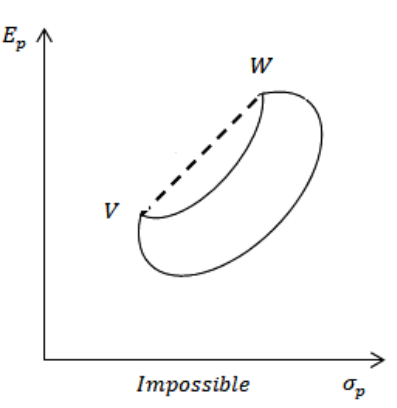

c

Figure 7. Possible situations when combining portfolios $V$ and $W$

The appearance of the feasible region will depend on the constraints imposed on the investor. Figure $8 \mathrm{a}$ to $\mathrm{d}$ shows four major cases that can be encountered.

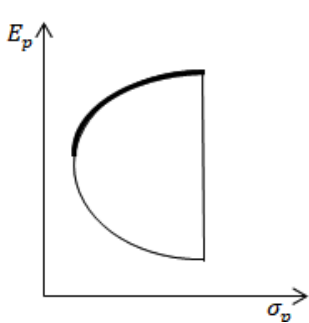

$\boldsymbol{a}$

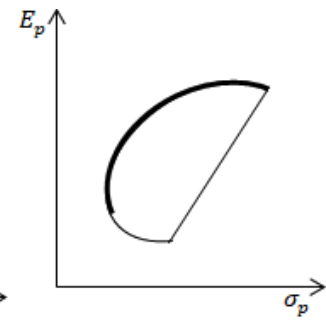

$b$

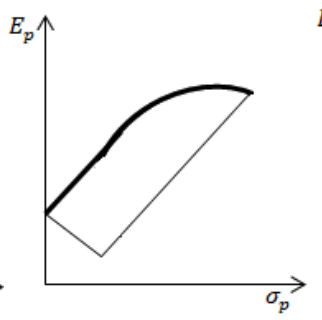

c

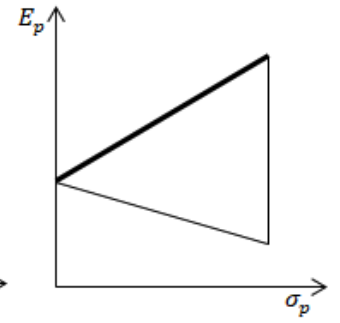

$d$

Figure 8. Possible cases that depend on the constraints imposed on the investor

Figure $8 a$ and $b$ are cases in which no security provides a certain return. Figure $8 c$ and $d$ include such a security. In the cases shown in figure $8 b$ and $c$, the investor cannot consider securities, and in the other two figures $8 a$ and $d$ can ensure the issuance of securities.

As shown in Figures $8 c$ and $d$, the evolution of $E_{p}, \sigma_{p}$ efficient can be linear.

It should be noted that if two portfolios are placed along an efficient linear segment of $E_{p}, \sigma_{p}$, their yields must be perfectly correlated, because otherwise the combinations of the two portfolios would give $E_{p}, \sigma_{p}$, values above the connecting line the two points, but this line should be the effective border and thus the yields of the two portfolios should be perfectly correlated.

In order to make decisions, we need to eliminate the uncertainty expressed in terms of the standard deviation of profitability. For calculation purposes, it is recommended to use the standard deviation square and the yield variance. 
The characteristics of a portfolio can be presented by a point in a graph $E_{p}, \sigma_{p}$. The points representing all feasible portfolios will be located in an area such as the one shown in Figure $9 a$. Top portfolios are effective. All others are ineffective.

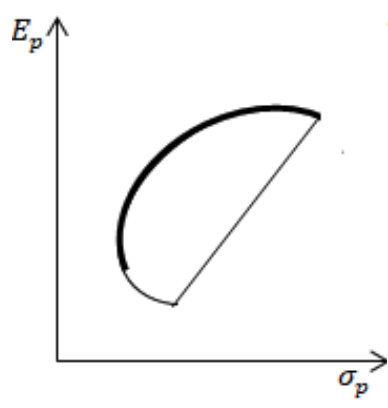

$a$

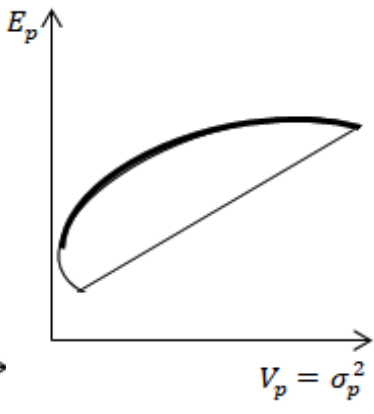

b

Figure 9. Representation of feasible portfolios

An alternative representation is shown in Figure $9 \mathrm{~b}$, in which each portfolio is represented by a point indicating the expected return $\left(E_{p}\right)$ and the variance of the return. $\left(V_{p}=\sigma_{p}^{2}\right)$. Portfolios are represented as a series of points in the feasible area $E_{p}, V_{p}$.

If we consider all portfolios with the same standard deviation of profitability $\sigma_{p}^{2}$, these to be effective in the area $E_{p}, V_{p}$ must have the highest value $E_{p}$. To be effective in the area $E_{p}, V_{p}$, an element of this group, must have the highest value of $E_{p}$. The efficient portfolio will be the same.

In other words, in a group of portfolios with the same value in $E_{p}$, efficiency dictates the selection of a portfolio with the lowest possible value $\left(\sigma_{p}\right)$.. Such a portfolio will have the lowest possible value of $\sigma_{p}^{2}\left(V_{p}\right)$. Using any criteria, the result will be the same.

To obtain the set of efficient portfolios it is easier if we identify the effective value of the area $E_{p}, V_{p}$. This becomes a simple problem because it involves converting to the area $E_{p}, V_{p}$, efficient to that of $E_{p}, V_{p}$.

The area $E_{p}, V_{p}$ will be a curve, and figure number $10 a$ and $b$ give two examples. If the area $E_{p}, V_{p}$, is linear, the area $E_{p}, V_{p}$ will increase.

Let $Y$ and $Z$ be any two points on the efficient area $E_{p}, V_{p}$. All points in the area between $Y$ and $Z$ will be above a straight line connecting the two points. Portfolio analysis techniques are designed to determine the efficiency of the $E_{p}, V_{p}$ area.

Portfolio analysis requires solving an optimization problem. Such an issue usually includes one or more decision variables, one or more constraints, and a goal that needs to be maximized or minimized. 


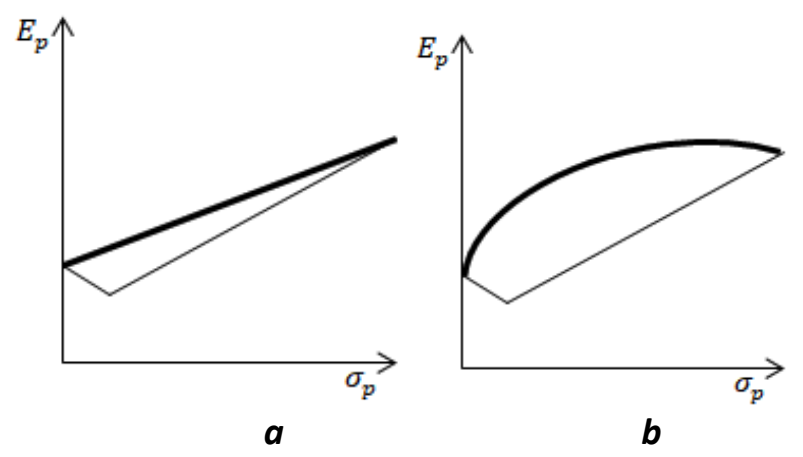

Figure 10. Efficiency of the area $E_{p}, V_{p}$ (curved or linear)

The variables underlying the decision are the proportions invested in various securities. A value must be assigned $X_{1}$ another $X_{2}, \ldots$, etc. There are $N$ titles, so there are $N$ different variables.

Different constraints may be placed on assigning values to those denoted by $t$. In negative cases, values may not be allowed. In other cases there is an upper limit on the amount invested in a particular security or group of securities. The set of constraints depends on the situation of the investor. The goal for a particular investor is to select the best portfolio or in other words, to find the portfolio feasible.

Figure $11 a$ and $b$ show the preferences of an investor $A$. The most important aspect of investor $A$ is shown in figure $11 a$. The lines drawn in a graph $E_{p}, V_{p}$ are parallel, so they are also linear. The larger a line, the more desirable the variant located along it.
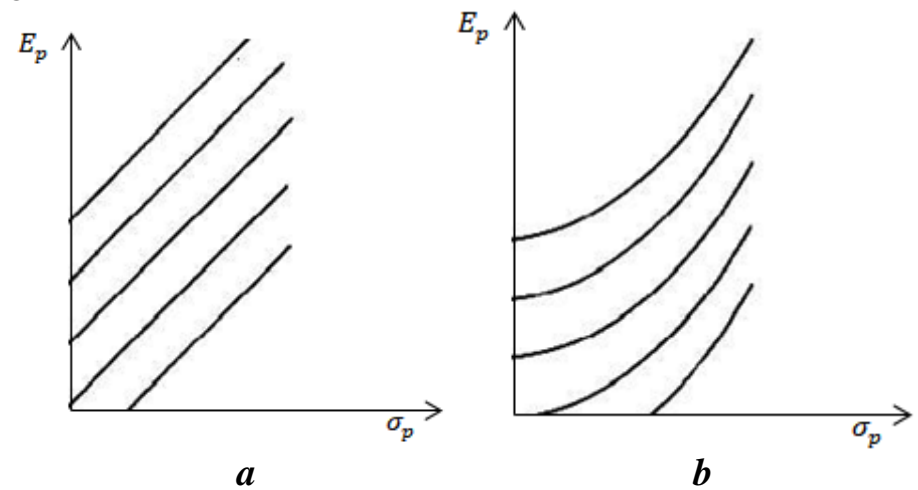

Figure 11. An investor's preferences

The problem of investor $A$ is to find the feasible combination $E_{p}, V_{p}$ stretched on the best achievable line. In figure number $12 a$ this element is in point $B$. The solution will have two important features, respectively: the selected portfolio will

DOI: 10.24818/18423264/55.2.21.19 
be efficient and at the selected point, the line will be tangent to the line. In other words, the line will touch the area, but will not intersect it.

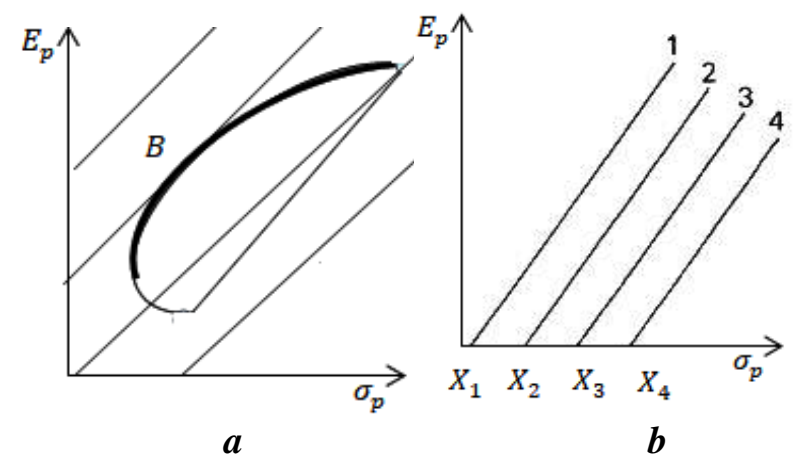

Figure 12. Feasible combination $E_{p}, V_{p}$ stretched on the best achievable line

The equation of any curve assumed by investor $A$ can be written in the form: $V_{p}=\alpha+\lambda E_{p}$

Figure number $12 b$ shows four selected lines. Their equations are:

$V_{p}=\alpha_{1}+\lambda E_{p} ; V_{p}=\alpha_{2}+\lambda E_{p} ; V_{p}=\alpha_{3}+\lambda E_{p} ; V_{p}=\alpha_{4}+\lambda E_{p}$

The value of $\lambda$ indicates the inclination of the line, the same for each curve. The value of $\alpha$ indicates the horizontal inclination, which differs from one line to another.

In other words, investor A's concern is to minimize $\alpha$. Under these conditions, the equation for any line will be of the form:

$$
\alpha=-\lambda E_{p}+V_{p}
$$

The objective becomes to minimize $-\lambda E_{p}+V_{p}$, where $E_{p}=\sum_{i=1}^{N} X_{i} E_{i}$ and $V_{p}=\sum_{i=1}^{N} \sum_{j=1}^{N} X_{i} X_{j} C_{i j}$. Considering thus the problem of investor $A$, in its entirety, it becomes: the identification of the variables $X_{1}, X_{2}, \ldots, X_{N}$; setting the minimization objective a $-\lambda \sum_{i=1}^{N} X_{i} E_{i}+\sum_{i=1}^{N} \sum_{j=1}^{N} X_{i} X_{j} C_{i j}$ and consideration of the basic constraints and any other relevant constraints, namely $\sum_{i=1}^{N} X_{i}=1$.

The attitude of investors regarding the expected return to profitability variance is given by $\lambda$ value. The higher the value of $\lambda$, the greater the interest $E_{p}$ with respect to $V_{p}$. Figure $13 a$ to $d$ illustrates this relationship. In figure number $13 a, \lambda$ is large enough to make $V_{p}$ insignificant. Investor $\mathrm{A}$ simply wants to maximize $E_{p}$, i.e. $-E_{p}$. Figure number $13 \mathrm{~d}$ illustrates the other extreme $\lambda=0$, in which the investor only wants to minimize $V_{p}$. The value of $\lambda$ indicates the importance to be given to relative $E_{p}$ and $V_{p}$. 


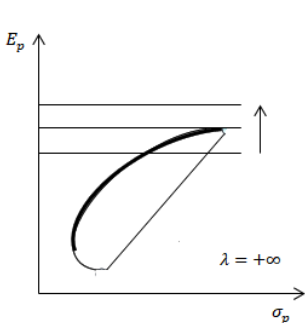

$\boldsymbol{a}$

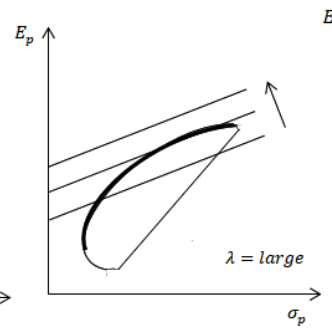

$b$

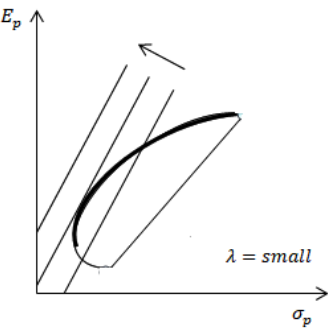

c

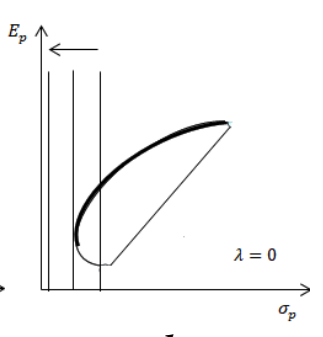

$d$

Figura 13: The interest $E_{p}$ with respect to $V_{p}$ depending on the value of $\lambda$

For any given value of $\lambda$, the solution to investor $A$ 's problem will be to provide an efficient portfolio. At the selected point, the line will be tangent to the area $E_{p}, V_{p}$. Two features of the efficient line of the area are especially relevant if its slope differs at each point and is vertical at the bottom, becoming progressively flatter to its tip. These result from the convexity of the line $E_{p}, V_{p}$ efficient and the relationship between $E_{p}$ and $\sigma_{p}$.

We assume that the problem of investor $A$ has been solved for each relevant value of $\lambda$. Thus, each efficient portfolio will be obtained. To identify the entire set of effective portfolios, we will minimize $-\lambda E_{p}+V_{p}$, for all possible values provided that $\lambda \geq 0$. This is the portfolio analysis when investor $\mathrm{A}$ has achieved its intended purpose.

From a practical point of view, portfolio analysis problems differ primarily through constraints. Of these, only one is essential, ie the proportions invested must add up to 1 .

A situation that does not involve other constraints can be considered a basic situation, ie it minimizes $-\lambda \sum_{i=1}^{N} X_{i} E_{i}+\sum_{i=1}^{N} \sum_{j=1}^{N} X_{i} X_{j} C_{i j}$, for all possible values of $\lambda \geq 0$, with the condition $\sum_{i=1}^{N} X_{i}=1$.

Such a situation can be easily resolved. Thus, one approach would be to assign a certain numeric value to $\lambda$ and after solving the problem, we get a specific set of numeric values for $X$. In any case this would provide a single efficient portfolio the whole procedure would have to be repeated each time. Therefore, $\lambda$ must be explicitly included in the calculations, the resulting solution being a series of equations of the form:

$$
X_{1}=K_{1}+k_{1} \lambda ; X_{2}=K_{2}+k_{2} \lambda ; \ldots X_{N}=K_{N}+k_{N} \lambda
$$

Where: $X_{1}, \ldots, X_{N}$ are variable (portfolios or securities);

$K_{1}, \ldots, K_{N}$ and $k_{1}, \ldots, k_{N}$ are constant.

Any efficient portfolio can be established by substituting the corresponding value of $\lambda$ in each equation, for example $\lambda=10$ results:

$$
\begin{aligned}
& X_{1}=K_{1}+10 k_{1} ; X_{2}=K_{2}+10 k_{2} ; \ldots X_{N}=K_{N}+10 k_{N} \\
& \text { For } \lambda=0, \text { result: } \\
& X_{1}=K_{1} ; X_{2}=K_{2} ; \ldots X_{N}=K_{N}
\end{aligned}
$$


$K_{i}=$ thus indicates the composition of the minimum variance portfolio.

The effective portfolio corresponding to any value given to $\lambda$ is indicated by the trajectory of the lines representing the securities.

In the absence of additional constraints, each value of $\lambda$ will provide a different efficient portfolio. We will consider the portfolios $\mathrm{C}$ and $\mathrm{R}$, obtained when $\lambda=0$ and $\lambda=\lambda^{*}$ (for very high values). Any efficient portfolio, which corresponds to an intermediate value of $\lambda$, can be considered a combination of portfolios $C$ and $R$, because each $X_{i}$ is linearly linked to $\lambda$. The relationship between the expected return of an efficient portfolio and the value of $\lambda$ will be at the same time linear.

The solution of this problem consists in determining it by substituting the obtained equations, resulting in:

$E_{p}=\sum_{i=1}^{N} X_{i} E_{i}=\sum_{i=1}^{N}\left(K_{i}+k_{i} \lambda\right) E_{i}=\sum_{i=1}^{N} K_{i} E_{i}+\left(\sum_{i=1}^{N} k_{i} E_{i}\right) \lambda$

Each of the amounts in parentheses is a number. Thus, the first is the expected return on the minimum variance portfolio, and the second indicates the expected additional return per unit of $\lambda$.

If at least two securities have different expected yields, the value $E_{p}$ will continue to increase as $\lambda$ increases. There will be no limit to the expected potential return, as the investor is allowed to issue an unlimited type of guarantee, using the proceeds to purchase a security with a higher expected return.

The relationship between the variance of the return of an efficient portfolio and the value of $\lambda$ that generates the portfolio will be quadratic. It can also be determined by substituting the obtained equations, resulting:

$V_{p}=\sum_{i=1}^{N} \sum_{j=1}^{N} X_{i} X_{j} C_{i j}=\sum_{i=1}^{N} \sum_{j=1}^{N}\left(K_{i}+k_{i} \lambda\right)\left(K_{j}+k_{j} \lambda\right) C_{i j}=$ $\sum_{i=1}^{N} \sum_{j=1}^{N} K_{i} K_{j} C_{i j}+\left(\sum_{i=1}^{N} \sum_{j=1}^{N} K_{i} k_{j} C_{i j}+k_{i} K_{j} C_{i j}\right) \lambda+\left(\sum_{i=1}^{N} \sum_{j=1}^{N} k_{i} k_{j} C_{i j}\right) \lambda^{2}$

Each of the amounts in parentheses will be a number, the first being the variance of the minimum variance portfolio, and the others indicate how $V_{p}$ increases by $\lambda$.

The efficient area equation will be a quadratic function of $V_{p}$ and can be obtained by combining the formulas for $E_{p}$ and $V_{p}$, eliminating $\lambda$.

It is not difficult to obtain the values $K_{i}$ and $k_{i}$ for a given situation.

Most portfolio analysis situations are complicated to fit the specifications of the baseline situation. Values that can be assigned to variables are usually constrained in different ways. Such constraints may take the form of equality or inequality. Normally, all terms involving variables are placed on the left side, leaving only one constant on the right side. Standard solving techniques require a linear function of the variables considered.

\section{Conclusions}

From the data presented in the article based on the study conducted by the authors on the model of analysis and establishment of efficient portfolios, a number of theoretical and practical conclusions can be drawn. First, the portfolios must be 
Model for Analysis and Construction of the Efficient Portfolios

a combination of the securities that go into the portfolio that the investor wishes to place on the capital market. Here he must take into account the establishment of the expected level of profitability, which can only be done on the basis of building an econometric model with the appropriate variables in order to determine parameters, based on which to estimate the final yield (profitability) of this portfolio security.

From the study carried out on the different variants involved in establishing the model to ensure the achievement of an efficient portfolio, a series of conclusions can be deduced, the most important of which are first of all the correct choice of variables, which can influence the final profitability; establishing the correlation that exists between the securities entering the portfolio; determining the market risk that may spread during the period in which the securities portfolio is placed; highlighting possible other variables, which can have an influence on the efficiency of the portfolio and last but not least the forecasting on a probabilistic basis of the return of the portfolio placed in the capital market. Based on these well-selected variables and put in full accordance with the situation of each security, which is included in the portfolio, parameters can be determined, which are the basis for a more accurate estimate of yield.

The issue of divergences, the issue of constraints and other elements that manifest themselves in the capital market are also studied very carefully in order to be able to detach the best outlined model, which would lead to the estimation of the best return. Of course, the best return depends not only on the size of the investments of the placed assets, but also on how they can be influenced by other factors during the period in which it is placed in the capital market.

In order to achieve a precise econometric model for building efficient portfolios, the investor must make several correlated, comparative studies, so that he can choose the most convenient option, which ensures a more accurate return.

Another conclusion is that most portfolio analysis situations are complicated to fully fit the basic situation from which to start. In this sense, values can be attributed to variables that are constrained by certain situations that may occur in the market. Therefore, this aspect must also be studied in order for the investor to be able to reach a real dimension of the securities that he includes in his portfolio.

Another precise situation is the standard portfolio analysis, which must be addressed when obtaining the set of efficient top portfolios. We say top portfolios, because of all the options it can calculate, determine, the investor appears a certain structure that is the most convenient, not always with the highest return, but with the guarantee of achieving that return, probably the safest.

In studies based on econometric models for building efficient portfolios, the investor should consider several options, which he can then adjust if one variant emerges from the others and which ensures higher stability.

DOI: $10.24818 / 18423264 / 55.2 .21 .19$ 
Constantin Anghelache, Mădălina-Gabriela Anghel, Ștefan Virgil Iacob

\section{REFERENCES}

[1] Altăr, M. (2002), Teoria portofoliului; www.dofin.ase.ro;

[2] Amenc, N., Le Sourd, V. (2003), Theorie du Portefeuille et Analyse de sa Performance, Editura Economica, Paris;

[3] Ameur, H.B., Prigent, J.L. (2010), Behaviour towards Risk in Structured Portfolio Management. International Journal of Economics and Finance, 2(5), 91-102;

[4] Armeanu, D. (2008), Rentabilitatea şi riscul portofoliului format din două titluri. Romanian Statistical Review Supplement „România şi economia europeană”, 157-164;

[5] Baule, R. (2010), Optimal Portfolio Selection for the Small Investor Considering Risk and Transaction Costs. OR Spectrum, 32(1), 61-76;

[6] Buraschi, A., Porchia, P., Trojani, F. (2006), Correlation Risk and Optimal Portfolio Choice; AFA New Orleans Meetings Paper;

[7] Clemencon, S., Skander, S. (2007), On Portfolio Selection under Extreme Risk Measure: The Heavy-Tailed ICA Model. International Journal of Theoretical and Applied Finance, 10(03), 449-474;

[8] Cox, J., Huang, C.F. (1989), Optimal Consumption and Portofolio Policies when Asset Prices. Econometrica, 53(2), 385-407;

[9] Dragotă, V. (coordonator), Dragotă, M., Dămian, O.A., Stoian, A., Mitrică, E., Lăcătuş, C.M., Manaţe, D., Ţâţu, L., Hândoreanu C.A. (2009), Gestiunea portofoliului de valori mobiliare - ediţia a doua; Economică Publishing; Bucureşti;

[10] Geromichalos, A., Simonovska, I. (2011), Asset Liquidity and International Portfolio Choice, Working Paper 17331;

[11] Harvey, C.R. et al. (2010), Portofolio Selection with Higher Moments. Quantitative Finance, 10(5), 469-485;

[12] Iacob, Ș.V., Popovici, M., Radu, I. (2020), Model for Estimating and Testing the Maximum Probability. International Journal of Academic Research in Accounting, Finance and Management Sciences, 10(1), 220-228;

[13] Li, J., Smetters, K. (2011), Optimal Portfolio Choice with Wage-indexed Social Security; Working Paper 17025;

[14] Markowitz, H. (1959), Portofolio Selection. Efficient Diversification of Investment; John Wiley \& Sons Publishing House, New York;

[15] Merton, R.C. (1971), Optimum Consumption and Portfolio Rules in a Continuous Time Model. Journal of Economic Theory, 23, 373-413;

[16] Stancu, I. (2007), Finanţe. Vol 1. Pieţe financiare şi gestiunea portofoliului, Economică Publishing; Bucureşti;

[17] West, K.D. (2012), Econometric Analysis of Present Value Models when the Discount Factor is near one; Working Paper 18247. 